\title{
Screen-Time Policies and Practices in Early Care and Education Centers in Relationship to Child Physical Activity
}

\author{
Amanda E. Staiano, PhD,' Elizabeth Kipling Webster, PhD, Andrew T. Allen, MBA, \\ Amber R. Jarrell, BS, and Corby K. Martin, $\mathrm{PhD}^{1}$
}

\section{Abstract}

Background: Few preschool children meet physical activity recommendations, whereas the majority exceeds screen-time recommendations. The purpose of this study was to examine the relationship of screen-time policies and practices with children's physical activity and sedentary time in early care and education (ECE) centers.

Methods: We conducted a cross-sectional study of 104 children ( $3.3 \pm 0.5$ years; $50 \%$ girls) attending 10 ECE centers in the United States. Physical activity was measured by accelerometry. Screen-time practices were measured by classroom observation and director report. Mixed linear models were used to examine the relationship of screen-time practices with children's total physical activity (TPA) and moderate-to-vigorous physical activity (MVPA) and sedentary time, adjusting for child's age, sex, and BMI $z$-score and taking into account the clustering of children within each center. Models were repeated to include director-reported active play time as a covariate.

Results: More limited/supervised screen-time (by observation) was related to higher TPA ( $p=0.0003)$ and lower sedentary time $(p=0.0003)$. More limited/supervised screen-time (by director report) was related to higher TPA $(p<0.0001)$ and MVPA $(p=0.021)$ and lower sedentary time $(p<0.0001)$. Associations remained significant when active play time was included as a covariate. TPA was inversely related to computer access $(p=0.0015)$ and positively related to the use of educational screen-time compared with noneducational screen-time $(p=0.04)$.

Conclusions: Limiting computer usage and ensuring screen-time is educational, and integrated within the curriculum may benefit children's physical activity levels and reduce time spent sedentary.

Keywords: computer; locomotion; movement; preschool child; television

\section{Introduction}

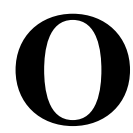
besity affects $13.7 \%$ of children aged $2-5$ years in the United States (US). ${ }^{1}$ Insufficient physical activity coupled with high amounts of sedentary time contribute to excess weight gain in children. ${ }^{2-5}$ Screen-time, which is time spent with TV, computers, or other hand-held screens, is a common sedentary activity of young children promoted by extensive marketing and device availability. ${ }^{6}$ Preschoolers spend 4.1 hours/day with a screen, ${ }^{7}$ exceeding guidelines of 1 hour/day, ${ }^{8-10}$ while less than half meet physical activity guidelines of $\geq 15$ minutes/h engaged in physical activity. ${ }^{11}$ Excessive screen-time has been associated with elevated BMI, shorter sleep, and emotional and cognitive delays in young children, ${ }^{8,12-15}$ although evidence of a direct link between preschoolers' screen-time and physical activity remains inconclusive. ${ }^{12,16-18}$

Children spend a large portion of their weekdays in nonparental care: $82 \%$ of US children aged $3-5$ years attended an early care and education (ECE) center in $2016 .{ }^{19}$ Physical activity is highly variable between centers, ${ }^{20,21}$ but is generally low: only $2 \%-3 \%$ of children's time was spent in moderate-to-vigorous physical activity (MVPA) based on accelerometry data collected from 281 children

'LSU's Pennington Biomedical Research Center, Baton Rouge, LA.

${ }^{2}$ School of Kinesiology, Louisiana State University, Baton Rouge, LA.

3Mayor's Healthy City Initiative, Baton Rouge, LA. 
attending nine preschools. ${ }^{21}$ Many centers provide children with access to digital screens; children engaged in between 0.1 and 1.3 hours/day of screen-time across seven studies. ${ }^{22}$ Furthermore, direct observations in 24 preschools revealed that $98 \%$ of screen-time ("video/screen") was sedentary. $^{23}$

Best practice guidelines for physical activity promotion in ECE centers include the reduction of sedentary activities. ${ }^{24,25}$ The present study was designed to address a gap in the literature specifically to examine screen-time practices and their potential relationship to children's physical activity, which was identified as a research priority for obesity prevention by expert consensus. ${ }^{26}$ Furthermore, previous examinations were limited to only examining minutes of screen-time and the presence of screens in the room ${ }^{18,25,27,28}$ without examining other screen-time policies and practices such as the educational content of the screen-time, children eating during screentime, providers using screens as rewards, provider supervision during screen-time, or parent or provider training on screen-time. Therefore, the purpose of the present study was to conduct a comprehensive examination of screen-time policies and practices and to examine relationships with children's physical activity and sedentary time. The Louisiana Department of Education enacted licensing regulations in 2015 that required ECE centers to have an electronic device policy limiting screen-time to 2 hours/day at child care, ${ }^{29}$ providing an opportune time to examine practices and potential impacts on children's behavior.

\section{Methods}

This study is a cross-sectional analysis of the baseline data collected in 2016-2017 for "Pause \& Play," a prospective cohort study that aims to examine the implementation of screen-time policies and practices in ECE centers in relationship to children's physical activity. ${ }^{29}$ As previously reported, ${ }^{29}$ the study was designed to occur in 10 ECE centers for sufficient power to compare children's MVPA between low vs. high supportive child care environments. $^{30}$

\section{ECE Centers}

The state Department of Education provided a list of licensed ECE centers in one parish (county), which was then randomized. ECE centers were contacted in order of randomization (146 centers were contacted; see Supplementary Fig. S1 for the CONSORT diagram; Supplementary Data are available online at www.liebertpub.com/ chi) to ultimately enroll 10 centers. Study staff contacted each center's director by telephone in order of randomization and confirmed eligibility criteria, which included being a licensed ECE Center located in East Baton Rouge Parish, enrollment of at least 18 children ages 3-4 years, and willing to participate. Directors provided informed consent during a scope visit. The study protocol was ap- proved by the Pennington Biomedical Institutional Review Board. Each ECE center received \$200 of school supplies for time and effort.

Centers were church-affiliated $(n=3)$, Head Start $(n=2)$, a corporate-sponsored center serving employees $(n=1)$, a privately owned and operated independent center $(n=1)$, a nonprofit/faith-based preschool $(n=1)$, affiliated with an elementary school $(n=1)$, or affiliated with a university $(n=1)$. All centers had been in operation for at least 10 years. All centers participated in the state's Quality Start rating system $(n=6)$ and/or the National Association for the Education of Young Children accreditation $(n=5)$. Four centers received child care assistance funding or state food program funding. Student enrollment included 70 children/center aged 3-4 years (range: 19-194).

\section{Child Participants}

Parents were notified about the study via informational handout, email/letter from director, and/or in-person informational session. No parent refused participation for the classroom observation. The full purpose of the study was not disclosed to children, parents, teachers, or directors until after data collection. Parents were invited to allow their child to participate in the accelerometry and height/ weight assessments. A child was eligible if aged 3-4 years; spent at least 6 hours/day, 5 days/week at the center; and planned to attend the same center the next year for followup (data forthcoming). A parent/guardian provided written informed consent. Children were not asked to provide assent due to their young age, but procedures were explained in child-friendly terms and a child could refuse to participate. One ECE center required documented verbal assent. Children received a toy for each day they wore their accelerometer $(\sim \$ 1 /$ child total $)$.

\section{Procedures}

Physical activity and sedentary time. Physical activity and sedentary time were measured by accelerometry at the right hip, secured by a neoprene belt (ActiGraph GT3X+, Ft. Walton Beach, FL). Parents and teachers were encouraged to have each child wear the accelerometer 24-hours/day for at least 7-days (plus an initial familiarization day and the morning of the final day).

Anthropometry. Height to the nearest $1.0 \mathrm{~cm}$ and weight to the nearest $0.1 \mathrm{~kg}$ were measured with children dressed in light clothing using a portable stadiometer and high-precision electronic scale, respectively.

Sociodemographic characteristics. Parents reported child's date of birth, sex, and race/ethnicity in a survey.

Center policies and practices. Ten screen-time policies/ practices were ascertained using director report and direct observation (Table 1). Director surveys were based on the 
Table I. Screen-Time Policies and Practices Based on Director Report and Classroom Observation Across 10 Early Care and Education Centers

\begin{tabular}{|c|c|c|c|c|}
\hline Component & Item & $\begin{array}{l}\text { Dichotomized } \\
\text { response }\end{array}$ & $\begin{array}{l}\text { Director } \\
\text { report }\end{array}$ & Observed \\
\hline \multirow[t]{2}{*}{ I. Screen-time policy } & \multirow{2}{*}{$\begin{array}{l}\text { At our child care facility, a written policy on } \\
\text { electronic devices in preschool classrooms: }\end{array}$} & Does not exist & 0 & 0 \\
\hline & & Is written & 10 & 10 \\
\hline \multirow[t]{2}{*}{ 2. Screen-time allowed } & \multirow{2}{*}{$\begin{array}{l}\text { For preschool children, the amount of screen } \\
\text { time allowed at child care center is: }\end{array}$} & Any allowed & 6 & 6 \\
\hline & & None allowed & 4 & 4 \\
\hline \multirow[t]{2}{*}{ 3. Television access } & \multirow[t]{2}{*}{ In preschool classrooms, televisions are: } & Accessible to children & 4 & 5 \\
\hline & & Not accessible to children & 6 & 5 \\
\hline \multirow[t]{3}{*}{ 4. Computer access } & \multirow[t]{3}{*}{ Among preschool children, computers are: } & Each child allowed & \multirow[t]{2}{*}{3} & \multirow[t]{2}{*}{4} \\
\hline & & $\geq 30$ minutes/day & & \\
\hline & & Each child allowed $\leq 15$ minutes/day & 7 & 6 \\
\hline \multirow[t]{2}{*}{ 5. Educational } & \multirow{2}{*}{$\begin{array}{l}\text { For preschool children, their television/DVD } \\
\text { viewing at school includes: }\end{array}$} & Some/mostly educational contents & 3 & 3 \\
\hline & & All educational contents & 7 & 7 \\
\hline \multirow[t]{2}{*}{ 6. Eating occasions } & \multirow{2}{*}{$\begin{array}{l}\text { For preschool children, television/DVD viewing } \\
\text { during meals or snack time occurs: }\end{array}$} & Some of the time & 1 & 3 \\
\hline & & Rarely or never & 9 & 7 \\
\hline \multirow[t]{2}{*}{ 7. Screens as reward } & \multirow{2}{*}{$\begin{array}{l}\text { Television/video viewing is used as a reward in } \\
\text { preschool children's classrooms: }\end{array}$} & Some of the time & 0 & 0 \\
\hline & & Rarely or never & 10 & 10 \\
\hline \multirow[t]{2}{*}{ 8. Provider supervision } & \multirow{2}{*}{$\begin{array}{l}\text { During screen time activities with preschool } \\
\text { children, providers supervise and watch with the } \\
\text { children: }\end{array}$} & Rarely/some of the time & 2 & 0 \\
\hline & & All of the time & 8 & 10 \\
\hline \multirow[t]{2}{*}{ 9. Provider training } & \multirow{2}{*}{$\begin{array}{l}\text { Providers are offered training opportunities on } \\
\text { screen time reduction and/or media literacy for } \\
\text { preschool children: }\end{array}$} & Rarely or never & 6 & 6 \\
\hline & & One or more times per year & 4 & 4 \\
\hline \multirow[t]{2}{*}{ 10. Parent training } & \multirow{2}{*}{$\begin{array}{l}\text { Parents of preschool children are offered screen } \\
\text { time reduction and/or media literacy education } \\
\text { (e.g., special programs, newsletters, or } \\
\text { information sheets): }\end{array}$} & Rarely or never & 6 & 6 \\
\hline & & One or more times per year & 4 & 4 \\
\hline
\end{tabular}

Nutrition and Physical Activity Self-assessment for Child Care (NAPSACC) ${ }^{31}$ and also included information on physical activity practices. The item used for the present analysis was "Active play time [indoor and outdoor] is provided to all preschool children, including children with special needs" with five response choices: 45 minutes/day or less, 46-60 minutes/day, 60-90 minutes/day, 90-120 minutes/day, more than 120 minutes/day.

A day-long observation of one classroom at each ECE center was conducted by one of two trained research specialists following the physical activity components of the Environment and Policy Assessment and Observation (EPAO) tool. ${ }^{25,28}$ Each observation began at the start of the teacher's class to the end (average observation of 7.5 hours). Recordings included any screen-time, including type, duration, and content; screens present in the room; screen-time used during an eating occasion or as a reward; and provider's presence during screen-time. Before data collection, the research specialists completed over 20 hours of training with $\geq 95 \%$ agreement during two practice observation periods.

\section{Statistical Analysis}

BMI $z$-score and percentile were calculated. ${ }^{32}$ Accelerometry data were stored as 15 -second intervals ${ }^{33}$ and spliced to include time spent at preschool based on start/stop time of each classroom observation. For the present analysis, a valid day was considered complete accelerometry data from the start to stop time of the classroom observation day. Only accelerometry data during the classroom observation day for students in the observed classrooms were used. Cutpoints were based on Pate et al. ${ }^{34}$ Total physical activity (TPA) included light, moderate, and vigorous intensity, whereas MVPA included moderate and vigorous intensity. Fifty-seven children were excluded from the present analysis because they were not students in the observed classrooms. These children did not differ from the analytic sample by age, sex, race/ethnicity, or BMI $z$-score. 
A summary score characterizing each center's screentime policies and practices was created using 10 components from the director's survey $\left(\right.$ ScreenLimit $_{\text {director }}$ ) or

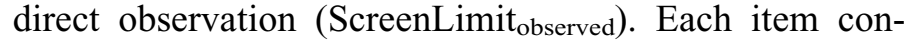
sisted of 4-5 response choices; these were dichotomized and a composite score was created by summing scores for all components (range: $0-10$ ), with 0 representing the most access to screens and 10 representing the most limits/ supervision of screen-time.

The analytic sample included 104 children. Mixed models were used to examine the relationship of summary screen score with children's activity levels. Covariates included child's age, sex, and BMI $z$-score, ${ }^{35}$ taking into account the clustering of children within center. Models were repeated for each dependent variable: TPA, MVPA, or sedentary time. Models were repeated with directorreported active play time as a covariate based on associations with physical activity in ECE centers. ${ }^{25}$ Each model was repeated to examine each policy/practice component as the independent variable. Statistical analysis was performed using SAS 9.4.

\section{Results}

Children who enrolled in the study were aged $3.3 \pm 0.5$ years, including $50 \%$ girls. The race distribution included 54\% White, 34\% African American, 8\% Asian, and 4\% Mixed/Other race; also, the ethnicity distribution included $5 \%$ Hispanic. Fifteen percent of children were overweight, and $7 \%$ had obesity.

Children had complete accelerometry data for $4.0 \pm$ 1.0 days (range: $1-5$ preschool days). During the observed classroom period, children spent $50 \%$ of the time engaged in sedentary time and $50 \%$ engaged in TPA, including $15 \%$ of the total period engaged in MVPA. Specifically, children engaged in $3.7 \pm 0.6$ hours of TPA (including $1.1 \pm 0.4$ hours/day of MVPA) and 3.8 \pm 0.6 hours of sedentary time at preschool; only two children did not attain at least 15 minutes/h of TPA, while 39\% engaged in less than 1 hour/ day MVPA at preschool (Table 2).

\section{Screen-Time Policies and Practices}

Based on director report, ScreenLimit director score was 7.3 \pm 1.0. Centers met eight $(n=5)$, seven $(n=1)$, six $(n=3)$, or five $(n=1)$ components. Higher ScreenLimit director $_{\text {(in- }}$ dicating more limits/supervision) was associated with higher levels of children's TPA $(p<0.0001)$ and MVPA $(p=0.021)$ and less sedentary time $(p<0.0001)$. When active play time was included as a covariate, ScreenLimit director $_{\text {. }}$ remained significantly associated with higher levels of TPA $(p=0.015)$ and less sedentary time $(p=0.015)$ but not MVPA.

Based on direct observation, ScreenLimit ${ }_{\text {observed }}$ was 6.4 \pm 1.2. Centers met eight $(n=1)$, seven $(n=3)$, six $(n=4)$, five $(n=1)$, or three $(n=1)$ components. Higher ScreenLimit ${ }_{\text {observed }}$ was associated with higher levels of TPA $(p=0.0003)$ and less sedentary time $(p=0.0003)$ but

\begin{tabular}{|c|c|c|c|}
\hline & $\begin{array}{c}\text { Boys, } \\
(n=52)\end{array}$ & $\begin{array}{c}\text { Girls, } \\
(n=52)\end{array}$ & $\begin{array}{c}\text { All, } \\
(n=104)\end{array}$ \\
\hline Age, years & $3.4 \pm 0.5$ & $3.3 \pm 0.5$ & $3.3 \pm 0.5$ \\
\hline BMI z-score & $0.1 \pm 1.1$ & $0.3 \pm 1.2$ & $0.2 \pm 1.1$ \\
\hline BMI percentile & $53.7 \pm 30.0$ & $59.9 \pm 30.9$ & $56.8 \pm 30.3$ \\
\hline \multicolumn{4}{|l|}{$\begin{array}{l}\text { Activity at school, } \\
\text { hours/day }\end{array}$} \\
\hline Sedentary & $3.7 \pm 0.8$ & $3.9 \pm 0.5$ & $3.8 \pm 0.6$ \\
\hline Total physical activity & $3.8 \pm 0.8$ & $3.6 \pm 0.5$ & $3.7 \pm 0.6$ \\
\hline MVPA & $1.2 \pm 0.4 *$ & $1.0 \pm 0.3$ & $1.1 \pm 0.4$ \\
\hline
\end{tabular}

Values are mean \pm standard deviation. Physical activity includes light, moderate, and vigorous physical activity; MVPA includes moderateto-vigorous physical activity.

Significant sex difference notated by $* p<0.05$.

not significantly associated with MVPA $(p=0.096)$. With active play time as a covariate, ScreenLimit ${ }_{\text {observed }}$ remained significantly associated with higher levels of children's TPA $(p=0.033)$ and less sedentary time $(p=0.033)$ but not MVPA.

Screen-time policy. Directors at all 10 centers reported having a written screen-time policy; upon observation, the state policy ${ }^{29}$ was posted for display in all centers. Without variance, further analysis was not possible.

Screen-time allowed. Four directors reported no screentime, five reported $<30$ minutes/day, and one reported 30 minutes to 1 hour/day. There was more screen-time allowed based on observation: two allowed 30 minutes to 1 hour/day and one allowed 1-2 hours/day, but no child exceeded the 2 hour/day state regulation. ${ }^{29}$ Children's TPA, MVPA, and sedentary time did not vary based on whether there was screen-time allowed based on director report or observation.

TV access. Six directors reported no TVs available for children's use and four provided varying access [in most classrooms $(n=1)$, in some classrooms $(n=1)$, or stored outside classrooms except for occasional use $(n=2)]$. TVs were observed in five classrooms; two were in centers where the director reported no TVs. Four classrooms had a DVD player; no video games or electronic toys were observed. Children's TPA, MVPA, and sedentary time did not vary by children's access to TV based on director report or observation. No TV time was observed.

Computer access. Computer access was variable, with most directors $(n=7)$ reporting no access or $<15$ minutes/ day $(n=3)$. Children attending centers that reported offering 
$\leq 15$ minutes/day of computer use had higher engagement in TPA $(p=0.0015)$ and lower sedentary time $(p=0.0015)$ than others, but MVPA did not differ.

Computers were the only screens observed [in seven classrooms, including desktop computers $(n=5)$, Smartboard $(n=1)$, and tablets/iPads $(n=1)]$. One computer was in a center where the director reported no computers. Children's TPA, MVPA, and sedentary time did not vary by observed computer access. Computer usage totaled 232 minutes at five centers, averaging 46.4 minutes of total screen-time in each (range: 27-85 minutes). Observed computer activities included "Dora the Explorer" game and Microsoft Paint on a desktop computer; a PBS activity on a Smartboard; and literacy, maze, and puzzle games on iPads built into a table. There were two adult-led computer activities for the entire classroom, including a teacher demonstrating a cartoon learning computer game for 30minutes and an outside technology group delivering a 30minute lesson on how to use desktop computers.

Educational nature of screen-time. Seven directors reported that TV/DVD viewing at preschool included only commercial-free, age-appropriate, educational programming that was integrated with the curriculum, with one director reporting mostly and two reporting some. In centers where directors reported only using appropriate TV/DVD content integrated within the curriculum, children engaged in more TPA $(p=0.04)$ and MVPA $(p=0.03)$ and less sedentary time $(p=0.04)$.

Eating occasions. Nine directors reported rarely/never allowing TV/DVD viewing during meals/snacks; one director reported allowing this some of the time. Screen-time during eating occasions was observed at three centers. Children's TPA, MVPA, and sedentary time did not vary by eating occasions in front of the screen based on director report or observation.

Screens as rewards. All directors reported never/rarely using screens as rewards, and there were no observations of screens used as rewards. Without variance, further analysis was not possible.

Provider supervision. Most directors reported that providers supervise and watch children during screen-time activities all the time; one reported some of the time and one reported rarely/never. During observations, providers were always present in the room during screen-time. Children's TPA, MVPA, and sedentary time did not vary by provider supervision based on director report or observation.

Provider and parent training. Four directors reported providing screen reduction and media literacy training to providers at least yearly, and five directors reported providing training to parents. There were no differences in children's TPA, MVPA, or sedentary time between these groups.

\section{Discussion}

Policies and practices limiting screen time in ECE centers were significantly related to children's TPA, MVPA, and sedentary time. These relationships persisted independent of minutes of active play, suggesting that screen-time practices influence children's activity levels independently from physical activity practices. Specific policies/practices related to computer usage were more influential: higher computer access was related to less physical activity, whereas providing only educational screen-time rather than noneducational screen-time was related to more physical activity. The 10-component screen-time policies/practices tool may be useful for researchers and practitioners to more comprehensively evaluate the influence of screen-time in ECE centers on children's activity levels, particularly by including an examination of all types of screen usage and not only TV viewing.

The main results are in the expected direction but do contradict two prior studies in 29 centers that observed the reverse relationship: increased access to $\mathrm{TVs} /$ computers was related to higher physical activity levels in children. ${ }^{25,30}$ These data were collected before 2006, and associations may be confounded by centers with screen access also having greater financial resources and staff training. ${ }^{25}$ Now that screens are becoming more readily accessible across income and education levels, ${ }^{36}$ an inverse association between screen practices and young children's physical activity is emerging indicating the importance of monitoring screen usage at ECE centers.

No screen-time was observed in five centers, whereas the other five centers provided on average 46 minutes/day screen-time: this falls in the middle of the $0.1-1.3$ hours/ day of screen-time at ECE centers observed in previous studies. $^{22}$ Because the state's regulations allow up to 2 hours/day screen-time at the ECE center, every center in the present study met the state policy. Yet, allowing 2 hours/day exceeds current national guidelines of 1 hour/ day total screen-time ${ }^{8-10}$ and does not take into account children's screen-time outside of the ECE center. Therefore, more restrictive state policies are needed to ensure that children do not exceed screen-time limits throughout the day.

The amount of observed computer usage is higher than previous reports, such as a study of 842 ECE centers conducted in 2010-2012, in which 64\% reported limiting computer time to $\leq 1$ hour/week. ${ }^{37}$ ECE centers now include other screen devices, including desktop computers, tablets/iPads, and Smartboards; indeed, all observed screen-time in the present study was computer-based. Since previous studies observed TV viewing as the predominant or exclusive screen-time, ${ }^{22,38,39}$ the present findings contribute updated information on screen usage in ECE centers and indicate that children's screen usage in ECE settings is diversifying beyond TV.

Most of the screen-time content was deemed by the directors as educational, age-appropriate, and integrated into 
the curriculum, which aligns with a study of 168 child care facilities, in which over $90 \%$ of directors reported that TV was used for educational or educational and entertainment purposes. ${ }^{39}$ In the present study, centers that only used educationally appropriate content also had more physically active and less sedentary children. The present study observed two instances of adult-led screen-time integrated within the curriculum; the other screen-time was independent play with content predominantly focused on literacy and math skills. Examining not only duration but also quality of screen-time aligns with the American Academy of Pediatrics guidelines, ${ }^{8}$ which recommend that screentime should be high-quality programming that is coviewed with an adult who helps children understand what they are seeing and apply what they learn. Similar approaches are endorsed by Canadian and Australian guidelines. ${ }^{9,10}$ Based on these guidelines, screen-time policies and practices should include recommendations on the educational content/quality and the role of an adult to coview and integrate screen-time within the educational context.

All centers had a written screen-time policy, which may be attributed to state regulation ${ }^{29}$ and national guidelines ${ }^{8}$ that caution practitioners on the negative associations of screen-time and young children's development. While many of the directors' reported practices aligned with classroom observation, the few discrepancies indicate that the directors' policies and expectations are not necessarily implemented in the classroom. Therefore, the classroom observation of practices was an important objective measure in addition to the director-report.

Children's physical activity levels were higher than previous estimates. The majority (61\%) of children exceeded 1 hour/day MVPA, contrasting a review in which children failed to meet this threshold in 9 of 10 studies. $^{40}$ One reason for this discrepancy may be inconsistencies in physical activity measurement among preschool children ${ }^{41-43}$; the Pate et al. cut-points were selected for the present study because these were validated against indirect calorimetry in preschool children. ${ }^{34}$ However, using the same cut-points, nearly all children met guidelines of $>15$ minutes/h TPA in the present study, whereas just half of children met the recommended 15 minutes/h TPA in two studies of 38 ECE centers. ${ }^{11}$ Reasons for this higher prevalence of physical activity, such as improved physical activity practices and environments, warrant further investigation. Interventions to promote physical activity and reduce screen-time may need to focus on centers where children are not meeting physical activity guidelines, as well as specifically support individual children who do not meet recommendations.

Future research should explore other factors that may influence screen-time policies and practices, including the centers' rating on the Quality Start system. In addition, the training of providers and parents in media literacy and screen-time reduction strategies is an opportunity for improvement, as training was not offered by many centers. Provider training contributes to healthy weight-related practices in child care centers, ${ }^{39}$ and parent training may reduce the likelihood of using screens as a calming rather than educational tool. ${ }^{44}$ Other avenues of exploration include examining screen-time during eating occasions, of which there were three observed instances, for potential negative consequences for weight-related behaviors. ${ }^{45} \mathrm{Fu}$ ture research should also expand to family child care homes, as high TV usage has been reported for these settings. ${ }^{37,46}$

Strengths of the study include the use of the EPAO, which is a validated tool and highly cited in the international literature, the use of accelerometry to objectively measure children's physical activity, diversity among the children and ECE centers, and the extensive focus on screen-time usage and practices. Limitations of this study include limited generalizability as all 10 centers were located in one city, although the centers were diverse in type, size of student enrollment, and receipt of government funding. A second limitation is the use of 1 day's observation in one classroom in each center, although observations were scheduled to not conflict with special events, field trips, or bad weather. While the teachers and director were not explicitly told the reason for the study until after data collection, it is possible that social desirability bias led teachers to change their practices during the observation period.

In conclusion, children were more physically active and less sedentary in ECE centers that limited children's screen-time, particularly those that limited access to computers and ensured that content was educational and integrated within the curriculum. A comprehensive screentime assessment may help practitioners and researchers to better understand the potential utility and harms of screentime on young children's behavior.

\section{Acknowledgments}

We gratefully acknowledge the ECE center directors, parents, and children who participated in this study, as well as the research assistants who helped with data collection. The "Pause \& Play" project was supported by Award Number U54 MD008602 for the Gulf States Collaborative Center for Health Policy Research (Gulf States-HPC) from the National Institute on Minority Health and Health Disparities of the National Institutes of Health, and by a gift from the American Council on Exercise. A.E.S. is supported, in part, by 1 U54 GM104940 from the National Institute of General Medical Sciences of the National Institutes of Health, which funds the Louisiana Clinical and Translational Science Center. C.K.M. is supported, in part, by the NORC Center Grant P30 DK072476 entitled "Nutrition and Metabolic Health through the Lifespan" sponsored by NIDDK. The content is solely the responsibility of the authors and does not necessarily represent the official views of the National Institutes of Health.

\section{Author Disclosure Statement}

No competing financial interests exist. 


\section{References}

1. Skinner AC, Ravanbakht SN, Skelton JA, et al. Prevalence of obesity and severe obesity in US children, 1999-2016. Pediatrics 2018;141:e20173459.

2. Koplan JP, Liverman CT, Kraak VI. Preventing Childhood Obesity: Health in the Balance. National Academies Press: Washington, DC, 2005

3. Ekelund U, Luan J, Sherar L, et al. Moderate to vigorous physical activity and sedentary time and cardiometabolic risk factors in children and adolescents. JAMA 2012;307:704-712.

4. Tremblay M, LeBlanc A, Kho M, et al. Systematic review of sedentary behaviour and health indicators in school-aged children and youth. Int J Behav Nutr Phys Act 2011;8:98.

5. Jago R, Baranowski T, Baranowski J, et al. BMI from 3-6y of age is predicted by TV viewing and physical activity, not diet. Int $J$ Obes Relat Metab Disord 2005;29:557-564.

6. Strasburger VC, Hogan MJ, Mulligan DA, et al. Children, adolescents, and the media. Pediatrics 2013;132:958-961.

7. Tandon PS, Zhou C, Lozano P, et al. Preschoolers' total daily screen time at home and by type of child care. J Pediatr 2011;158: 297-300.

8. AAP Council on Communications and Media. Media and young minds. Pediatrics 2016;138:e20162591.

9. Tremblay MS, Chaput J-P, Adamo KB, et al. Canadian 24-Hour Movement Guidelines for the Early Years (0-4 years): An integration of physical activity, sedentary behaviour, and sleep. $B M C$ Public Health 2017;17:874.

10. Okely AD, Ghersi $\mathrm{D}$, Hesketh $\mathrm{KD}$, et al. A collaborative approach to adopting/adapting guidelines-The Australian 24-Hour Movement Guidelines for the early years (Birth to 5 years): An integration of physical activity, sedentary behavior, and sleep. $B M C$ Public Health 2017; 17:869.

11. Pate RR, O'Neill JR, Brown WH, et al. Prevalence of compliance with a new physical activity guideline for preschool-age children. Child Obes 2015;11:415-420.

12. Cox R, Skouteris H, Rutherford L, et al. Television viewing, television content, food intake, physical activity and body mass index: A cross-sectional study of preschool children aged 2-6 years. Health Promot J Austr 2012;23:58-62.

13. Suglia SF, Duarte CS, Chambers EC, et al. Social and behavioral risk factors for obesity in early childhood. $J$ Dev Behav Pediatr 2013;34:549.

14. Dennison BA, Erb TA, Jenkins PL. Television viewing and television in bedroom associated with overweight risk among lowincome preschool children. Pediatrics 2002;109:1028-1035.

15. Hinkley T, Verbestel V, Ahrens W, et al. Early childhood electronic media use as a predictor of poorer well-being: A prospective cohort study. JAMA Pediatr 2014;168:485-492.

16. Hinkley T, Crawford D, Salmon J, et al. Preschool children and physical activity: A review of correlates. Am J Prev Med 2008;34: 435-441.e437.

17. Copeland KA, Khoury JC, Kalkwarf HJ. Child care center characteristics associated with preschoolers' physical activity. Am J Prev Med 2016;50:470-479.

18. Ross ST, Dowda M, Saunders R, et al. Double dose: The cumulative effect of TV viewing at home and in preschool on children's activity patterns and weight status. Pediatr Exerc Sci 2013;25: $262-272$.
19. Corcoran L, Steinley K, Grady S. Early Childhood Program Participation, Results from the National Household Education Surveys Program of 2016. U.S. Department of Education; NCES 2017-101. 2017.

20. Finn K, Johannsen N, Specker B. Factors associated with physical activity in preschool children. J Pediatr 2002;140:81-85.

21. Pate RR, Pfeiffer KA, Trost SG, et al. Physical activity among children attending preschools. Pediatrics 2004;114:1258-1263.

22. Vanderloo LM. Screen-viewing among preschoolers in childcare: A systematic review. BMC Pediatr 2014;14:205.

23. Brown WH, Pfeiffer KA, McIver KL, et al. Social and environmental factors associated with preschoolers' non-sedentary physical activity. Child Develop 2009;80:45-58.

24. McWilliams C, Ball SC, Benjamin SE, et al. Best-practice guidelines for physical activity at child care. Pediatrics 2009;124: $1650-1659$.

25. Bower JK, Hales DP, Tate DF, et al. The childcare environment and children's physical activity. Am J Prev Med 2008;34:23-29.

26. Ward DS, Vaughn A, Story M. Expert and stakeholder consensus on priorities for obesity prevention research in early care and education settings. Child Obes 2013;9:116-124.

27. Chang-Martinez C, Ahmed NU, Natale RA, Messiah SE. Statemandated nutrition, physical activity, and screen time policies in child care centers. Health Promot Pract 2018;19:411-417.

28. Ward D, Hales D, Haverly K, et al. An instrument to assess the obesogenic environment of child care centers. Am J Health Behav 2008;32:380-386.

29. Staiano AE, Allen A, Fowler W, et al. State licensing regulations on screen-time in childcare centers: An impetus for participatory action research. Prog Community Health Partnersh 2018;12:101109.

30. Dowda M, Pate RR, Trost SG, et al. Influences of preschool policies and practices on children's physical activity. J Community Health 2004;29:183-196.

31. Ward D ME, McWilliams C, Vaughn A, et al. Go NAP SACC: Nutrition and Physical Activity Self-Assessment for Child Care, 2nd Edition. Center for Health Promotion and Disease PRevention and Department of Nutrition, University of North Carolina at Chapel Hill, 2014.

32. Centers for Disease Control and Prevention. A SAS program for the CDC growth charts. 2011. Available at www.cdc.gov/nccdphp/ dnpao/growthcharts/resources/sas.htm Last accessed July 9, 2015.

33. Pate RR, O'Neill JR, Mitchell J. Measurement of physical activity in preschool children. Med Sci Sports Exerc 2010;42:508-512.

34. Pate RR, Almeida MJ, McIver KL, et al. Validation and calibration of an accelerometer in preschool children. Obesity 2006;14:2000 2006.

35. Pfeiffer KA, Dowda M, McIver KL, et al. Factors related to objectively measured physical activity in preschool children. Pediatr Exerc Sci 2009;21:196-208.

36. Anderson M. Technology device ownership: 2015. Pew Research Center, 2015. Available at www.pewinternet.org/2015/10/29/ technology-device-ownership-2015 Last accessed February 1, 2018 .

37. Natale R, Page M, Sanders L. Nutrition and physical activity practices in childcare centers versus family childcare homes. Early Child Educ J 2014;42:327-334.

38. Christakis DA, Garrison MM, Zimmerman FJ. Television viewing in child care programs: A national survey. Commun Rep 2006;19: 111-120. 
39. Christakis DA, Garrison MM. Preschool-aged children's television viewing in child care settings. Pediatrics 2009;124:16271632.

40. Reilly JJ. Low levels of objectively measured physical activity in preschoolers in child care. Med Sci Sports Exerc 2010;42: 502-507.

41. Hnatiuk JA, Salmon J, Hinkley T, et al. A review of preschool children's physical activity and sedentary time using objective measures. Am J Prev Med 2014;47:487-497.

42. Puyau MR, Adolph AL, Vohra FA, et al. Validation and calibration of physical activity monitors in children. Obesity 2002;10: $150-157$.

43. Sirard JR, Trost SG, Pfeiffer KA, et al. Calibration and evaluation of an objective measure of physical activity in preschool children. $J$ Phys Act Health 2005;2:345-357.

44. Radesky JS, Peacock-Chambers E, Zuckerman B, et al. Use of mobile technology to calm upset children: Associations with social-emotional development. JAMA Pediatr 2016;170:397399.

45. Bellissimo N, Pencharz PB, Thomas SG, et al. Effect of television viewing at mealtime on food intake after a glucose preload in boys. Pediatr Res 2007;61:745.

46. Trost SG, Messner L, Fitzgerald K, et al. Nutrition and physical activity policies and practices in family child care homes. $\mathrm{Am} \mathrm{J}$ Prev Med 2009;37:537-540.

Address correspondence to:

Amanda E. Staiano, PhD

LSU's Pennington Biomedical Research Center 6400 Perkins Road Baton Rouge, LA 70808

E-mail: amanda.staiano@pbrc.edu 